OPEN ACCESS

Edited by:

Akio Adachi,

Kansai Medical University, Japan

Reviewed by:

Tony Schountz,

Colorado State University,

United States

Felicity Jane Burt,

National Health Laboratory Service

(NHLS), South Africa

${ }^{*}$ Correspondence:

David A. Schwartz

davidalanschwartz@gmail.com

Specialty section:

This article was submitted to

Emerging and Reemerging Viruses,

a section of the journal

Frontiers in Virology

Received: 27 April 2021

Accepted: 10 May 2021

Published: 04 June 2021

Citation:

Schwartz DA (2021) Prioritizing the Continuing Global Challenges to

Emerging and Reemerging Viral Infections. Front. Virol. 1:701054.

doi: 10.3389/fviro.2021.701054

\section{Prioritizing the Continuing Global Challenges to Emerging and Reemerging Viral Infections}

\author{
David A. Schwartz* \\ Department of Pathology, Medical College of Georgia, Augusta University, Augusta, GA, United States
}

Keywords: emerging viral disease, epidemic, Arbovirus, reemerging viral disease, virus, pandemic, pathogenic viruses

This article discussing the importance of emerging viral diseases during the second year of the most consequential global viral pandemic to have occurred in many decades may, at first glance, appear redundant. However, it is still relevant-the coronavirus disease 2019 (COVID-19) pandemic has highlighted a multitude of significant gaps in public health preparedness throughout the world that have existed for many years, and now have exacerbated the spread and human suffering caused by this emerging viral infection. The COVID-19 pandemic has provided yet another example of the vulnerabilities of our global public health networks and highlighted that lethal viral pathogens do not respect national borders or political beliefs. Despite previous epidemics of emerging viral diseases and warnings from public health officials, the continued deprioritization, lack of strategic planning, and deficiency in both fiscal and human investment in public health systems have critically impaired global capabilities of responding effectively to the COVID-19 pandemic. It has also revealed that many countries are deficient in having the minimum capacities required to rapidly detect and respond to known vulnerabilities and public health emergencies.

The Centers for Disease Control and Prevention (CDC) defines emerging infectious diseases as "infectious diseases whose incidence in humans has increased in the past 2 decades or threatens to increase in the near future" (1). Among all of the categories of emerging infectious diseases, emergent viral agents constitute the most severe threat to global populations. Emerging viral diseases are caused by a highly heterogeneous group of agents include previously undetected or unknown viruses; previously known viruses whose causative role in producing clinical disease has previously not been recognized; evolution of new genetic strains from previously identified viral agents; and known viruses that have spread to new geographic locations or new populations. Those viral agents whose role in causing human disease had significantly declined in the past, but have once again become prevalent as a cause of illness, are termed reemerging viral diseases.

During the past decades there have been novel viral agents discovered that have been the source of significant morbidity and mortality around the world-these include human immunodeficiency virus (HIV), Ebola virus, chikungunya virus, West Nile virus, Zika virus and currently severe acute respiratory syndrome virus 2 (SARS-CoV-2). Reemerging viral infections have contributed to this global public health predicament: dengue, influenza and yellow fever have resulted in epidemics and deaths. Emerging infectious disease outbreaks have historically been found to originate in wildlife, with approximately 75 percent being zoonotic agents originating from a wide range of wild animals that are distributed throughout the world. Among the notable recent episodes of outbreaks and epidemics of emerging viruses having a zoonotic origin include Ebola virus with a putative reservoir in bats (2); Marburg virus having a reservoir in fruit bats (3), Lassa mammarenavirus with a reservoir in the multimammate rat (Mastomys natalensis) (4), Sin Nombre orthohantavirus having a deer mouse (Peromyscus maniculatus) reservoir (5), and the human immunodeficiency viruses-HIV-1 which was first transmitted to humans from chimpanzees 
(Pan troglodytes troglodytes) in Central Africa around 1931, and HIV-2 arising in sooty mangabeys (Cercocebus atys atys) and jumping to humans in West Africa around $1940(6,7)$. Of great significance among these emerging and reemerging viral diseases are those that are vector borne, including dengue, chikungunya, Rift Valley fever, Zika, yellow fever, West Nile, Japanese encephalitis and others. For example, disease caused by dengue virus was almost unknown prior to the midtwentieth century but has now become the most common vector-borne viral disease in the world (8). The vectors of these viruses are typically, but not exclusively, bloodsucking mosquitos, with the greatest burden occurring throughout the tropical and subtropical regions of the world. Emerging and reemerging viral diseases are unique in that their investigation may involve specialists from a wide variety of fields including clinical physicians, pathologists, veterinarians, epidemiologists, entomologists, zoologists, molecular biologists, public health specialists, anthropologists, and others $(9,10)$.

Public health agencies including the World Health Organization (WHO) have warned that infectious diseases have been emerging at alarming rates that had not been previously seen (11), and since the 1970s there have been approximately 40 new infectious diseases discovered. Prominent among emerging viral pathogens are the RNA viruses, with notable examples over the past 20 years including the severe acute respiratory syndrome coronavirus (SARS-CoV) in 20022003 in China, pandemic influenza (swine flu) A/H1N1 in 2009, the Middle East respiratory syndrome (MERS) coronavirus in 2012 in the Middle East, the West Africa Ebola virus disease epidemic in 2013-2015, the Zika virus pandemic in 2016-2017, and now the COVID-19 pandemic that began in China in late 2019. In addition to these newly identified agents, such previously recognized viral infections including pandemic influenza, yellow fever, measles, and others continue to pose a threat through the occurrence of new epidemics. The dengue virus is notable as the most significant and widespread flavivirus disease to have emerged globally, including a formerly rare form of the disease termed dengue hemorrhagic fever and its fatal counterpart-dengue shock syndrome (12). Emerging viruses often have the capability to cross borders rapidly and spread, exacerbated by the increasingly high and rapid mobility of people. Increasing use of airline travel has permitted infected persons to pass from one country to another in just a few hours; in 2019 and prior to the COVID-19 pandemic, airlines globally transported approximately 4.5 billion passengers (13). Unfortunately, outbreaks due to newly emergent and reemerging viruses may escape rapid recognition because of inadequate investment in public health including deficiencies in surveillance and reporting, public policy changes and failure to act in a timely manner following discovery of an outbreak.

The emergence of viral pathogens is a critically important public health issue that is associated with numerous complex etiological factors, the majority of which are have in common the dramatic increases of human activity and movements throughout the world. Most important among these causal factors are the rising frequency and speed of regional and global travel, expansion of human populations, increased flow of both animals and animal products with human assistance, alterations to the environment that modify the distribution of wild hosts and vectors and facilitate spread of infectious agents, and modifications in agricultural practices that can facilitate transfer of pathogens between wild and domestic animals (14-17). Global warming temperatures that result from ongoing climate change result in mosquitoes, together with the viral agents they transmit, to expand their range into regions where they previously had not been found. Climate change is also causing an increase in both the population and geographic distribution of ticks, resulting in the emergence and increasing prevalence of such tick-borne viral agents as Powassan virus, CrimeanCongo hemorrhagic fever virus, Heartland virus, Bourbon virus, tick-borne encephalitis virus, and others. Additional factors include the continued intrusion by humans on undeveloped lands and wildlife habitats, natural disasters including drought and famine, and the widespread prevalence of translocation of human populations due to conflict and refugee populations. A few examples include the reemergence of vampire bat rabies in the Amazon Basin due to deforestation and mining activities (18); outbreaks of Kyasanur forest disease resulting from clearcutting of forested land (19); Nipah virus outbreaks in Malaysia resulting from deforestation and expansion of pig farming (20); and outbreaks of hepatitis E in refugee camps (21). Traditional local food markets and live animal markets (known as "wet markets") that are found in many parts of the world have been associated with emergence of novel viral zoonotic diseases (22). Both regional as well as global pandemics have previously originated from spread of infectious agents from animals to humans because of wet markets and illegal wildlife trafficking. The avian influenza epidemic caused by the H5N1 influenza virus began in Southeast Asia was directly associated with the sale of infected birds in a traditional market (23); the SARS outbreak of 2002-2004 has been associated with trade of civets and bats (24); and multiple outbreaks of Ebola virus in Africa have been linked with the consumption of bushmeat (14).

In the most recent example, the COVID-19 pandemic has been linked by some investigators with a large wet market in Wuhan, China-the Huanan Seafood Wholesale Market-where sale of wild animals may have been a source of zoonotic infection (25). However, recent data indicate that earlier cases of human infection had no association with this or any other market, and that the virus initially caused human illness in Hubei province in mid-October to mid-November 2019 prior to the first human case linked to the Huanan market $(26,27)$. It appears most probable that the source of the COVID-19 pandemic was derived from a naturally occurring reservoir among wildlife, although the animal(s) sources or intermediate hosts have not yet been recognized (28).

If history has taught us anything, it is that emerging viral infections can be similar to accidents-they often occur at unexpected times, under unpredictable situations, and with uncertain outcomes. And it is beyond any doubt that emerging viral infections will continue to occur. The current global COVID-19 pandemic is a prime example of the potential danger arising with previously unknown viral agents. Can we predict what the next emerging viral infection will be that we face? The 
WHO has addressed this important issue in their R\&D Blueprint, a global strategy and preparedness plan that addresses the rapid activation and implementation of research and development activities during future epidemics (29). A component of this plan is to identify infectious diseases that can pose a future risk to public health because of their capability to cause outbreaks or epidemics, and for which countermeasures are either few or unavailable (29). These diseases include Crimean-Congo hemorrhagic fever (CCHF); Ebola virus disease; Marburg virus disease; Lassa fever; MERS-CoV; SARS-CoV; Nipah and other henipaviral diseases; Rift Valley fever; Zika virus; and Disease X (30). Interestingly, when this was written in 2018, Disease X was considered to represent a serious international epidemic that could result from a novel pathogen that was not a recognized source of human disease-this prior to the recognition of SARSCoV-2 and COVID-19 in early 2000.

Human host factors also play a prime role in emerging and reemerging viral diseases. As in other infectious diseases, persons who are immunocompromised or have underlying medical conditions may be at increased risk for having poor outcomes from emerging viral diseases. Persons at the extremes of ageinfants, children, and the elderly, constitute special risk groups for emerging viral diseases, not only because they may have increased susceptibility and worse incomes from developing infections, but because they may have host-related limitations to receiving newly developed therapeutic agents and vaccines. In particular, pregnancy has been shown to represent a risk factor for poor maternal outcomes in some emerging viral diseases $(31,32)$.

Among the most important questions that typically arise when an outbreak of human infection due to an emerging virus occurs is whether it will cause illness in pregnant mothers, and if the virus can undergo vertical transmission to the developing fetus or newborn infant. Unfortunately, mother-to infant infection has occurred with many emerging viral agents, either prior to, during, or after delivery. These include viral agents of hemorrhagic fever such as filoviruses (Ebola and Marburg viruses) (33), arenaviruses

\section{REFERENCES}

1. Centers for Disease Control and Prevention. Emerging Infectious Diseases (2018). Available online at: https://www.cdc.gov/niosh/topics/ emerginfectdiseases/default.html (accessed April 21, 2021).

2. Koch LK, Cunze S, Kochmann J, Klimpel S. Bats as putative Zaire ebolavirus reservoir hosts and their habitat suitability in Africa. Sci Rep. (2020) 10:14268. doi: 10.1038/s41598-020-71226-0

3. Towner JS, Pourrut X, Albariño CG, Nkogue CN, Bird BN, Grard G, et al. Marburg virus infection detected in a common African bat. PLoS ONE. (2007) 2:e764. doi: 10.1371/journal.pone.0000764

4. Kouadio L, Nowak K, Akoua-Koffi C, Weiss S, Allali BK, Witkowski PT, et al. Lassa virus in multimammate rats, Côte d'Ivoire, 2013. Emerg Infect Dis. (2015) 21:1481-83. doi: 10.3201/eid2108.150312

5. Calisher CH, Root JJ, Mills JN, Rowe JE, Reeder SA, Jentes ES, et al. Epizootiology of Sin Nombre and El Moro Canyon hantaviruses, southeastern Colorado, 1995-2000. J Wildl Dis. (2005) 41:1-11. doi: 10.7589/0090-3558-41.1.1

6. Sharp PM, Hahn BH. The evolution of HIV-1 and the origin of AIDS. Philos Trans R Soc Lond B Biol Sci. (2010) 365:2487-94. doi: 10.1098/rstb.2010.0031
(Lassa virus) (34), retroviruses (HIV) (35), hepeviruses (hepatitis E virus) (36), and flaviviruses (Zika virus) (37). These emerging viruses have the capacity to be transmitted transplacentally and cause fetal infection, often with disastrous results, and are now considered to be TORCH agents. Besides these agents there are two pathogenic coronaviruses-MERS-CoV and SARS-CoVthat were first identified in the last 20 years and have also caused this concern (38). These two emergent coronaviruses caused illness and death of pregnant women well as well as perinatal deaths, but there were no confirmed cases of placental infection or vertical transmission identified $(39,40)$. The most recent example of vertical transmission of an emerging virus has been the identification of transplacental infection of fetuses as well as postpartum infection of neonates with SARS-CoV-2 $(40,41)$, where the virus can infect not only the mother but also the placenta, fetus, and newborn.

Emerging viral infections have affected the entire course of human history and been the source of immeasurable human misery and death. Considering the ongoing status of the current COVID-19 pandemic, now in its fourth wave in some countries and with emerging viral variants continuing to develop, they will continue to do so for the foreseeable future. Throughout the centuries, emerging infections have, together with armed conflicts and natural disasters, created major challenges to human progress and survival. Emerging and reemerging viruses will continue to create unpredictable epidemics and difficult challenges in preventing widespread morbidity and mortality. Governments and institutions must prioritize assistance to the global scientific, medical, allied science, and public health communities so that we are prepared for the next emerging virus when it occurs.

\section{AUTHOR CONTRIBUTIONS}

The author confirms being the sole contributor of this work and has approved it for publication.

7. Lemey P, Pybus OG, Wang B, Saksena NK, Salemi M, Vandamme AM. Tracing the origin and history of the HIV-2 epidemic. Proc Natl Acad Sci USA. (2003) 100:6588-92. doi: 10.1073/pnas.0936469100

8. Huntington MK, Allison J, Nair D. Emerging vector-borne diseases. Am Fam Phys. (2016) 94:551-57.

9. Schwartz DA, Bryan RT, Hughes JM. Pathology and emerging infections-quo vadimus? Am J Pathol. (1995) 147:1525-33.

10. Schwartz DA, Bryan RT. Infectious disease pathology and emerging infections: are we prepared? Arch Pathol Lab Med. (1996) 120:117-24.

11. World Health Organization. International Spread of Disease Threatens Public Health Security (2007). Available online at: https://www.who.int/mediacentre/ news/releases/2007/pr44/en/ (accessed April 23, 2021).

12. Gubler DJ. Dengue and dengue hemorrhagic fever. Clin Microbiol Rev. (1998) 11:480-97.

13. International Civil Aviation Organization. The World of Air Transport in 2019 (2019). Available online at: https://www.icao.int/annual-report-2019/ Pages/the-world-of-air-transport-in-2019.aspx (accessed April 18, 2021).

14. Chomel BB, Belotto A, Meslin FX. Wildlife, exotic pets, and emerging zoonoses. Emerg Infect Dis. (2007) 13:6-11. doi: 10.3201/eid1301. 060480 
15. Bengis RG, Leighton FA, Fischer JR, Artois M, Mörner T, Tate CM. The role of wildlife in emerging and re-emerging zoonoses. Rev Sci Tech. (2004) 23:497511.

16. Cutler SJ, Fooks AR, van der Poel WH. Public health threat of new, reemerging, and neglected zoonoses in the industrialized world. Emerg Infect Dis. (2010) 16:1-7. doi: 10.3201/eid1601.081467

17. Piret J, Boivin G. Pandemics throughout history. Front Microbiol. (2021) 11:631736. doi: 10.3389/fmicb.2020.631736

18. Schneider MC, Belotto A, Adé MP, Leanes LF, Correa E, Tamayo H, et al. Epidemiologic situation of human rabies in Latin America in 2004. Epidemiol Bull. (2005) 26:2-4.

19. Varma MGR. Kyasanur forest disease. In: Service MW, editor. The Encyclopedia of Arthropod-Transmitted Infections. New York, NY: CABI Publishing (2001). p. 254-60.

20. Daszak P, Cunningham AA, Hyatt AD. Anthropogenic environmental change and the emergence of infectious diseases in wildlife. Acta Trop. (2001) 78:10316. doi: 10.1016/s0001-706x(00)00179-0

21. Browne LB, Menkir Z, Kahi V, Maina G, Asnakew S, Tubman M, et al. Notes from the field: hepatitis E outbreak among refugees from South Sudan Gambella, Ethiopia, April 2014-January 2015. MMWR Morb Mortal Wkly Rep. (2015) 64:537.

22. Aguirre AA, Catherina R, Frye H, Shelley L. Illicit wildlife trade, wet markets, and COVID-19: Preventing future pandemics. World Med Health Policy. (2020). doi: 10.1002/wmh3.348. [Epub ahead of print].

23. Hayden F, Croisier A. Transmission of avian influenza viruses to and between humans. J Infect Dis. (2005) 192:1311-14. doi: 10.1086/444399

24. Wang LF, Eaton BT. Bats, civets and the emergence of SARS. Curr Top Microbiol Immunol. (2007) 315:325-44. doi: 10.1007/978-3-540-70962-6_13

25. Mizumoto K, Kagaya K, Chowell G. Effect of a wet market on coronavirus disease (COVID-19) transmission dynamics in China, 2019-2020. Int J Infect Dis. (2020) 97:96-101. doi: 10.1016/j.ijid.2020.05.091

26. Pekar J, Worobey M, Moshiri N, Scheffler K, Wertheim JO. Timing the SARS-CoV-2 index case in Hubei province. Science. (2021) 372:412-17. doi: $10.1126 /$ science.abf 8003

27. World Health Organization. WHO-convened Global Study of Origins of SARSCoV-2: China Part (2021).

28. Michelitsch A, Wernike K, Ulrich L, Mettenleiter TC, Beer M. SARS-CoV2 in animals: from potential hosts to animal models. Adv Virus Res. (2021). doi: 10.1016/bs.aivir.2021.03.004. [Epub ahead of print].

29. World Health Organization. WHO R\&D Blueprint (2019). Available online at: https://www.who.int/research-observatory/analyses/rd_blueprint/ en/ (accessed April 25, 2021).

30. Coronagraphs. WHO Blueprint List of Priority Diseases (2018). Available online at: https://coronagraphs.com/blueprint/ (accessed April 25, 2021).

31. Schwartz DA. Pregnant women, vaccine development for emerging and epidemic viral infections and maternal immunization: human rights and the global survival of mothers and infants. Curr Trop Med Rep. (2019) 6:179-85. doi: 10.1007/s40475-019-00196-9

32. Schwartz DA. Being pregnant during the Kivu Ebola virus outbreak in DR Congo: the rVSV-ZEBOV vaccine and its accessibility by mothers and infants during humanitarian crises and in conflict areas. Vaccines. (2020) 8:38. doi: $10.3390 /$ vaccines 8010038

33. Schwartz DA, Anoko JN, Abramowitz S, Editors. Pregnant in the Time of Ebola: Women and Their Children in the 2013-2015 West African Epidemic. New York, NY: Springer (2019).

34. Price ME, Fisher-Hoch SP, Craven RB, McCormick JB. A prospective study of maternal and fetal outcome in acute Lassa fever infection during pregnancy. BMJ. (1988) 297:584-87. doi: 10.1136/bmj.297.6648.584

35. Brocklehurst P, French R. The association between maternal HIV infection and perinatal outcome: a systematic review of the literature and meta-analysis. Br J Obstet Gynaecol. (1998) 105:836-48. doi: 10.1111/j.1471-0528.1998.tb10227.x

36. Wu C, Wu X, Xia J. Hepatitis E virus infection during pregnancy. Virol J. (2020) 17:73. doi: 10.1186/s12985-020-01343-9

37. Schwartz DA. Viral infection, proliferation, and hyperplasia of Hofbauer cells and absence of inflammation characterize the placental pathology of fetuses with congenital Zika virus infection. Arch Gynecol Obstet. (2017) 295:1361-68. doi: 10.1007/s00404-017-4361-5

38. Schwartz DA, Graham AL. Potential maternal and infant outcomes from coronavirus 2019-nCoV (SARS-CoV-2) infecting pregnant women: lessons from SARS, MERS, and other human coronavirus infections. Viruses. (2020) 12:194. doi: 10.3390/v12 020194

39. Schwartz DA, Dhaliwal A. Infections in pregnancy with COVID-19 and other respiratory RNA virus diseases are rarely, if ever, transmitted to the fetus: experiences with coronaviruses, parainfluenza, metapneumovirus respiratory syncytial virus, and influenza. Arch Pathol Lab Med. (2020) 144:920-28. doi: 10.5858/arpa.2020-0211-SA

40. Schwartz DA, Levitan D. Severe acute respiratory syndrome coronavirus 2 (SARS-CoV-2) infecting pregnant women and the fetus, intrauterine transmission and placental pathology during the coronavirus disease 2019 (COVID-19) pandemic: it's complicated. Arch Pathol Lab Med. (2021). doi: 10.5858/arpa.2021-0164-ED. [Epub ahead of print].

41. Schwartz DA, Baldewijns M, Benachi A, Bugatti M, Collins RRJ, De Luca D, et al. Chronic histiocytic intervillositis with trophoblast necrosis are risk factors associated with placental infection from coronavirus disease 2019 (COVID19) and intrauterine maternal-fetal severe acute respiratory syndrome coronavirus 2 (SARS-CoV-2) transmission in liveborn and stillborn infants. Arch Pathol Lab Med. (2020) 145:517-28. doi: 10.5858/arpa.2020-0771-SA

Conflict of Interest: The author declares that the research was conducted in the absence of any commercial or financial relationships that could be construed as a potential conflict of interest.

Copyright (c) 2021 Schwartz. This is an open-access article distributed under the terms of the Creative Commons Attribution License (CC BY). The use, distribution or reproduction in other forums is permitted, provided the original author(s) and the copyright owner(s) are credited and that the original publication in this journal is cited, in accordance with accepted academic practice. No use, distribution or reproduction is permitted which does not comply with these terms. 